\title{
Synthesis Characterization and Biological Activities of Coordination Compounds of 4-Hydroxy-3-nitro-2H-chromen-2-one and Its Aminoethanoic Acid and Pyrrolidine-2-carboxylic Acid Mixed Ligand Complexes
}

\author{
Temitayo Aiyelabola, ${ }^{1}$ Ezekiel Akinkunmi, ${ }^{2}$ Efere Obuotor, ${ }^{3}$ \\ Idowu Olawuni, ${ }^{3}$ David Isabirye, ${ }^{4}$ and Johan Jordaan ${ }^{5}$ \\ ${ }^{1}$ Department of Chemistry, Obafemi Awolowo University, Ile-Ife, Osun State, Nigeria \\ ${ }^{2}$ Department of Pharmaceutics, Obafemi Awolowo University, Ile-Ife, Osun State, Nigeria \\ ${ }^{3}$ Department of Biochemistry and Molecular Biology, Obafemi Awolowo University, Ile-Ife, Osun State, Nigeria \\ ${ }^{4}$ Department of Chemistry, North-West University, Mafikeng Campus, Mmabatho, South Africa \\ ${ }^{5}$ Focus Area Chemical Resource Beneficiation, North-West University, Potchefstroom Campus, Potchefstroom, South Africa \\ Correspondence should be addressed to Temitayo Aiyelabola; ttlhaye@yahoo.com
}

Received 3 September 2016; Accepted 27 November 2016; Published 7 February 2017

Academic Editor: Claudio Pettinari

Copyright (c) 2017 Temitayo Aiyelabola et al. This is an open access article distributed under the Creative Commons Attribution License, which permits unrestricted use, distribution, and reproduction in any medium, provided the original work is properly cited.

Coordination compounds of 4-hydroxy-3-nitro-2H-chromen-2-one and their mixed ligand complexes with aminoethanoic acid and pyrrolidine-2-carboxylic acid were synthesized by the reaction of $\mathrm{Cu}(\mathrm{II})$ and $\mathrm{Zn}$ (II) salts in molar ratio $1: 2$ for the coumarin complexes and 1:1:1 for the mixed ligand complexes, in basic media. The compounds formed were characterized using infrared, Uvvis spectrophotometric analyses, mass spectrometry, magnetic susceptibility measurements, and EDX analyses. It was concluded that 4-hydroxy-3-nitro- $2 \mathrm{H}$-chromen-2-one coordinated as a monobasic ligand for all the complexes; it also coordinated via the carbonyl moiety in the case of the $\mathrm{Cu}(\mathrm{II})$ mixed ligand complexes. Similarly it was proposed that the amino acids also coordinated in a bidentate fashion via their amino nitrogen and carboxylate oxygen atoms. The synthesized compounds were screened for their antimicrobial and cytotoxic activities. The complexes exhibited marginal antimicrobial activity but good cytotoxic activity.

\section{Introduction}

Coumarins are a group of oxygen heterocyclic compounds which have attracted much attention as a result of their varied pharmacological properties which include antibacterial, anticoagulants, antibiotic, antifungal, anticancer, and antiinflammatory [1-10]. In addition, these compounds are used as additives in food and cosmetics, as dispersed fluorescent brightening agents, and as dyes for tuning lasers [11-16]. This broad array of usage has led to the increased interest in its various derivatives $[9,10,16-18]$. Of interest is the 4-hydroxy3-nitro- $2 \mathrm{H}$-chromen-2-one derivative, hnc (Figure 1) [9, 10,
$16,17]$. This is partly due to the presence of the carbonyl, nitro and hydroxo moieties in this compound, for which it may be considered as a versatile polyfunctional ligand $[9,10,16,17]$. Thus it may behave as an $\mathrm{O}$-monodentate ligand as well as an $O, O$-bidentate chelating agent $[9,10,16,17]$. Its coordination chemistry is therefore of interest to the coordination chemist. Published reports, in which hnc coordinated as a neutral ligand and in others as a monobasic bidentate ligand, suggest that its coordination behaviour is a function of the $\mathrm{pH}$ of the reaction $[9,10,16,17]$. In more recent times an area of focus of coordination chemists is that of mixed ligand complexes. This is because they are the most general and probable form of 

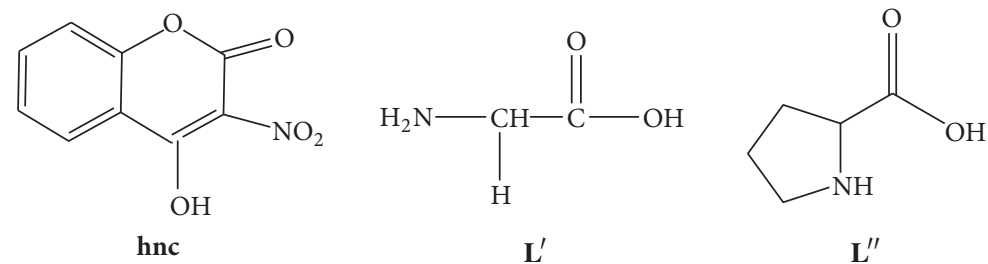

Figure 1: Structures of the ligands.

coordination compounds in the biological system [9, 19-22]. Therefore studies of mixed ligand complexes of biologically important compounds may serve as models for biochemical processes $[20,23,24]$. They are also characterized by their extreme stability and the fact that the chemical individuality and peculiarities of the central metal ion is more pronounced in these complexes [19].

It has been shown from previous reports that coordination of metal ions to biologically active agents may improve their efficiency and accelerate their bioactivity [2531]. Furthermore, earlier studies have also shown that some coordination compounds of coumarin derivatives and that of amino acids exhibited promising antimicrobial and cytotoxic activities on chelation [9, 32-44]. Few studies have however been conducted on coordination compounds of pyrrolidine2-carboxylic acid, a nonpolar amino acid, as well as mixed ligand complexes of hnc and amino acids. As a result of resistance to current drugs and emerging new diseases there is constant need of obtaining antimicrobial and anticancer agents with minimal side effects. The reported widespread applications of the coumarin moiety, amino acids, and their coordination compounds, therefore, informed our interest in the syntheses of novel mixed ligand complexes containing hnc and amino acids with the aim of obtaining more potent antimicrobial and cytotoxic agents with possible minimal side effects. Hence in this work we report the syntheses, characterization of $\mathrm{Cu}$ (II) and $\mathrm{Zn}$ (II) coordination compounds of 4-hydroxy-3-nitro- $2 \mathrm{H}$-chromen-2-one and their mixed ligand complexes with aminoethanoic acid $\left(\mathbf{L}^{\prime}\right)$ and pyrrolidine2-carboxylic acid $\left(\mathbf{L}^{\prime \prime}\right)$, Figure 1 , their antimicrobial activity, and brine shrimp lethality bioassay.

\section{Materials and Methods}

The chemicals and solvents used were of analytical grade and were used without further purification. The infrared spectra were recorded in the region $4000-499 \mathrm{~cm}^{-1}$ on a FourierTransform infrared spectrophotometer at North-West University, Mafikeng Campus. Electronic spectra were measured on a Varian Cary 50 ultraviolet-visible spectrophotometer also at the North-West University; measurements were made from 200 to $800 \mathrm{~nm}$. Magnetic susceptibility measurements were carried out at room temperature in the Department of Chemistry, Kwara State University, Ilorin, using a Sherwood scientific balance with $\left[\mathrm{HgCo}(\mathrm{SCN})_{4}\right]$ as standard. EDX analyses were obtained using Shimadzu Ray ny EDX 720 at the Department of Chemistry North-West University, Mafikeng Campus. The mass spectrum was obtained at the laboratory for analytical services, North-West University, Potchefstroom, on a Bruker Ser\# micrOTOF-Q II 10390 mass spectrometer, using matrix assisted laser desorption ionization. Screening of the compounds for antimicrobial activity was done at the Pharmaceutics laboratory Obafemi Awolowo University Ile-Ife. Brine shrimp lethality assay was carried out at the Department of Biochemistry and Molecular Biology Obafemi Awolowo University Ile-Ife.

The compounds were synthesized using adaptation of previous reports by Creaven et al., 2005 [9]. Compound 1 has been previously synthesized, characterized, and screened for antimicrobial activity by Creaven et al., 2005 [9]. The equations of the reactions are given in (1)-(5).

Coumarin Ternary complexes:

$$
\mathrm{M}_{(\mathrm{aq})}+2 \mathbf{h n c}_{(\mathrm{aq})} \longrightarrow\left[\mathrm{M}(\mathbf{h n c})_{2}\left(\mathrm{H}_{2} \mathrm{O}\right)_{2}\right]_{(\mathrm{aq})},
$$

where $\mathrm{M}=\mathrm{Cu}(\mathrm{II}), \mathrm{Zn}(\mathrm{II})$.

Mixed ligand complexes:

$$
\begin{aligned}
& 2 \mathrm{CuCl}_{2} \cdot 2 \mathrm{H}_{2} \mathrm{O}_{(\mathrm{aq})}+2 \mathbf{h n c}_{(\mathrm{aq})}+2 \mathbf{L}_{(\mathrm{aq})}^{\prime} \\
& \longrightarrow\left[\left(\mathrm{Cu}(\mathbf{h n c}) \mathbf{L}^{\prime}\right)_{2}\left(\mathrm{H}_{2} \mathrm{O}\right)\right]_{(\mathrm{aq})} \\
& \mathrm{ZnCl}_{2(\mathrm{aq})}+\mathbf{h n c}_{(\mathrm{aq})}+\mathbf{L}_{(\mathrm{aq})}^{\prime} \\
& \longrightarrow\left[\mathrm{Zn}(\mathbf{h n c})\left(\mathbf{L}^{\prime}\right)\left(\mathrm{H}_{2} \mathrm{O}\right)_{2}\right]_{(\mathrm{aq})} \\
& 2 \mathrm{CuCl}_{2} \cdot 2 \mathrm{H}_{2} \mathrm{O}_{(\mathrm{aq})}+2 \mathbf{h n c}_{(\mathrm{aq})}+2 \mathbf{L}^{\prime \prime}{ }_{(\mathrm{aq})} \\
& \longrightarrow\left[\left(\mathrm{Cu}(\mathbf{h n c}) \mathbf{L}^{\prime \prime}\right)_{2}\left(\mathrm{H}_{2} \mathrm{O}\right)\right]_{(\mathrm{aq})} \\
& \mathrm{ZnCl}_{2(\mathrm{aq})}+\mathbf{h n c}_{(\mathrm{aq})}+\mathbf{L}_{(\mathrm{aq})}^{\prime \prime} \\
& \longrightarrow\left[\mathrm{Zn}(\mathbf{h n c})\left(\mathbf{L}^{\prime \prime}\right)\left(\mathrm{H}_{2} \mathrm{O}\right)_{2}\right]_{(\mathrm{aq})},
\end{aligned}
$$

where hnc $=4$-hydroxy-3-nitro- $2 H$-chromen-2-one; $\mathbf{L}^{\prime}=$ aminoethanoic acid; $\mathbf{L}^{\prime \prime}=$ pyrrolidine-2-carboxylic acid.

\subsection{Syntheses of Coordination Compounds}

2.1.1. Compound 1. An aqueous solution of $\mathrm{CuCl}_{2} \cdot 2 \mathrm{H}_{2} \mathrm{O}$ $(1.72 \mathrm{~g}, 0.01 \mathrm{M})$ was added to a solution of $\mathrm{NaOH}(0.80 \mathrm{~g}$, $0.02 \mathrm{M}$ ) and 4-hydroxy-3-nitro- $2 \mathrm{H}$-chromen-2-one (4.17 g, $0.02 \mathrm{M}$ ) in water and the mixture was heated and stirred on a water bath for $2 \mathrm{~h}$ and then cooled. A green precipitate 
was obtained, which was recrystallized using ethanol-water mixture $(70 / 30 \mathrm{v} / \mathrm{v})$, washed, filtered, and dried in a vacuum oven at $60^{\circ} \mathrm{C}$ to give compound 1, Yield: $3.99 \mathrm{~g}$ (78\%), M.pt/d.t: $234-236^{\circ} \mathrm{C}$ (d). The complex was sparingly soluble in ethanol and methanol but soluble in water.

2.1.2. Compound 2. An aqueous solution of zinc(II) chloride $(1.36 \mathrm{~g}, 0.01 \mathrm{M})$ was added to a solution of $\mathrm{NaOH}$ $(0.80 \mathrm{~g}, 0.02 \mathrm{M})$ and 4-hydroxy-3-nitro- $2 \mathrm{H}$-chromen-2-one (hnc) $(4.21 \mathrm{~g}, 0.02 \mathrm{M})$ in water and the mixture was heated and stirred for $2 \mathrm{~h}$ on a water bath and then cooled. A yellow precipitate was obtained, which was recrystallized using ethanol-water mixture $(70 / 30 \mathrm{v} / \mathrm{v})$, washed, filtered, and dried in a vacuum oven at $60^{\circ} \mathrm{C}$ to give compound 2 , Yield: $3.43 \mathrm{~g}$ (67\%), M.pt/d.t: $245-246^{\circ} \mathrm{C}$ (d). The complex was sparingly soluble in ethanol, methanol, and water.

2.1.3. Compound 3. An aqueous solution of $\mathrm{CuCl}_{2} \cdot 2 \mathrm{H}_{2} \mathrm{O}$ $(1.72 \mathrm{~g}, 0.01 \mathrm{M})$ was added to a solution of $\mathrm{NaOH}(0.40 \mathrm{~g}$, $0.01 \mathrm{M}$ ) and 4-hydroxy-3-nitro-2H-chromen-2-one (hnc) $(2.02 \mathrm{~g}, 0.01 \mathrm{M})$ in water and the mixture was heated and stirred on a water bath. A solution of aminoethanoic acid $(0.75 \mathrm{~g}, 0.01 \mathrm{M})$ in ethanol-water mixture was added dropwise; the resultant mixture was heated for $2 \mathrm{~h}$. A bluish green precipitate was obtained, which was recrystallized using ethanol-water mixture $(70 / 30 \mathrm{v} / \mathrm{v})$, washed, filtered, and dried in a vacuum oven at $60^{\circ} \mathrm{C}$ to give 3, Yield: $3.26 \mathrm{~g}(78 \%)$, M.pt/d.t: $179-181^{\circ} \mathrm{C}(\mathrm{d}), \mathrm{M}^{+\bullet}(\mathrm{m} / \mathrm{z})$ : 705 . The complex was sparingly soluble in ethanol, methanol, and water.

2.1.4. Compound 4. An aqueous solution of zinc(II) chloride $(2.05 \mathrm{~g}, 0.015 \mathrm{M})$ was added to a solution of $\mathrm{NaOH}(0.61 \mathrm{~g}$, $0.015 \mathrm{M}$ ) and 4-hydroxy-3-nitro- $2 \mathrm{H}$-chromen-2-one (hnc) $(3.31 \mathrm{~g}, 0.015 \mathrm{M})$ in water and the mixture was heated and stirred on a water bath. Aminoethanoic acid $(1.13 \mathrm{~g}, 0.015 \mathrm{M})$ was added drop-wise with stirring; the mixture was then heated for $2 \mathrm{~h}$. A yellow precipitate was obtained, which was recrystallized, washed, filtered, and dried in a vacuum oven at $60^{\circ} \mathrm{C}$ to give 4, Yield: $3.60 \mathrm{~g}(63 \%)$, M.pt/d.t: $249-252$ (d). The complex was sparingly soluble in ethanol and methanol but soluble in water.

2.1.5. Compound 5. A solution of copper(II) chloride dihydrate $(1.71 \mathrm{~g}, 0.01 \mathrm{M})$ in water $(10 \mathrm{ml})$ was added to a solution of $\mathrm{NaOH}(0.40 \mathrm{~g}, 0.01 \mathrm{M})$ and hnc $(2.20 \mathrm{~g}, 0.01 \mathrm{M})$ in water $(10 \mathrm{ml})$; pyrrolidine-2-carboxylic acid $(1.16 \mathrm{~g}, 0.01 \mathrm{M})$ was added with stirring. The mixture was heated for $2 \mathrm{~h}$ and then cooled. Upon standing a bluish green precipitate was formed, which was filtered, washed with methanol and cold water, and then dried under vacuum at $60^{\circ} \mathrm{C}$. The solid was recrystallized from water, Yield: $3.14 \mathrm{~g}$ (46\%), M.pt/d.t.: 245-247 (d). The compound was sparingly soluble in ethanol and methanol but soluble in water.

2.1.6. Compound 6. A solution of zinc(II) chloride (1.38 g, $0.01 \mathrm{M})$ in water $(10 \mathrm{ml})$ was added to a solution of $\mathrm{NaOH}$ $(0.04 \mathrm{~g}, 0.01 \mathrm{M})$ and hnc $(2.09 \mathrm{~g}, 0.01 \mathrm{M})$ in water $(10 \mathrm{ml})$, pyrrolidine-2-carboxylic acid $(1.25 \mathrm{~g}, 0.01 \mathrm{M})$ was added drop-wise, and the mixture was heated with stirring for $2 \mathrm{~h}$. Upon standing a yellow precipitate formed, which was filtered, washed with methanol and cold water, and then dried under vacuum at $60^{\circ} \mathrm{C}$. The solid was recrystallized from water, Yield: $2.41 \mathrm{~g}(57 \%)$, M.pt/d.t: $280-283^{\circ} \mathrm{C}$ (d). The complex was sparingly soluble in ethanol and methanol but soluble in water.

2.2. Antimicrobial Methodology. The organisms used were five Gram-positive and three Gram-negative bacteria and two fungi, namely, S. aureus, S. epidermidis, B. subtilis $12, B$. subtilis 82, Clostridium, K. pneumonia, P. aeruginosa, E. Coli, C. albicans, and C. Pseudotropicalis. The agents were dissolved in water at room temperature or hot water as appropriate to give a concentration of $40 \mathrm{mg} / \mathrm{ml}$. The resulting solutions were used to soak sterile Whatman No. 2 discs (diameter = $6 \mathrm{~mm}$ ) and allowed to dry in an oven at $50^{\circ} \mathrm{C}$. The discs were then used to determine antibacterial and antifungal activities as previously described by Aiyelabola et al. 2012 [45]. Discs of imipenem and chlorhexidine were used as positive controls for bacteria and fungi, respectively. Zones of inhibition were used as indices of antimicrobial actions.

2.3. Cytotoxicity Bioassay. The procedure used was modified from the assay described by Solis et al., 1993 [46]. Brine shrimps (Artemia salina) were hatched using brine shrimp eggs in a conical shaped vessel $(1 \mathrm{~L})$, filled with sterile artificial seawater under constant aeration for $48 \mathrm{~h}$. After hatching, active nauplii free from egg shells were collected from brighter portion of the hatching chamber and used for the assay. Ten nauplii were drawn through a Pasteur pipette and placed in each vial containing $4.5 \mathrm{mg} / \mathrm{l}$ of brine solution. In each experiment, different volume of sample was added to $4.5 \mathrm{ml}$ of brine solution to give different concentration $(20,40$, 60,80 , and $100 \mu \mathrm{g} / \mathrm{ml}$ ) and maintained at room temperature for $24 \mathrm{~h}$ under the light. The surviving larvae were counted. Experiments were conducted along with control (vehicle treated), of the test substances in a set of three tubes per dose. Estimation of the $\mathrm{LC}_{50}$ values was estimated using probit analysis on a USEPA computer program.

\section{Results and Discussion}

3.1. Infrared. The infrared spectra analyses of ligands 4hydroxy-3-nitro- $2 H$-chromen-2-one, aminoethanoic acid, and pyrrolidine-2-carboxylic acid and their corresponding coordination compounds were carried out and the relevant peaks $\left(\mathrm{cm}^{-1}\right)$ are given in Table 1 . The spectral assignment was achieved by comparing the infrared spectra of the ligands with that of the complexes.

3.1.1. Compounds 1 and 2. The spectrum of the free ligand 4-hydroxy-3-nitro- $2 \mathrm{H}$-chromen-2-one, hnc, exhibited a sharp band at $1522 \mathrm{~cm}^{-1}$, attributable to $-\mathrm{NO}_{2}$ asymmetric absorption stretching frequency [47]. This was shifted in the spectrum of $\mathbf{1}$ and $\mathbf{2}$ to higher frequencies, thus serving as evidence of coordination of one of the oxygen atoms of the nitro group and is in agreement with previous reports 
TABLE 1: Relevant infrared spectra bands for the ligands and complexes $\left(\mathrm{cm}^{-1}\right)$.

\begin{tabular}{|c|c|c|c|c|c|c|c|c|c|}
\hline Bands & hnc & $\mathbf{L}^{\prime}$ & $\mathrm{L}^{\prime \prime}$ & 1 & 2 & 3 & 4 & 5 & 6 \\
\hline$\nu(\mathrm{O}-\mathrm{H})$ & 3435 & & & 3468 & 3526 & 3430 & 3446 & 3446 & 3580 \\
\hline$\nu(\mathrm{N}-\mathrm{O})$ & 1522 & & & 1557 & 1568 & 1560 & 1574 & 1573 & \\
\hline$v(\mathrm{C}-\mathrm{O}-\mathrm{H})$ & 1303 & & & & & & & & \\
\hline$\delta(\mathrm{O}-\mathrm{H})$ & & & & 1207 & 1214 & 1125 & 1202 & 1211 & 1216 \\
\hline$v(\mathrm{C}-\mathrm{O})$ & 1009 & & & 1057 & 1071 & 1046 & 1151 & 1068 & 1045 \\
\hline$\nu(\mathrm{C}=\mathrm{C})$ & 1601 & & & 1603 & 1607 & 1605 & 1608 & 1612 & 1603 \\
\hline$\nu(\mathrm{C}=\mathrm{O})$ & 1701 & & & 1652 & 1668 & & & & \\
\hline$\nu_{\mathrm{as}}(\mathrm{N}-\mathrm{H})$ & & 3196 & 3152 & & & 3301 & 3374 & 3233 & 3510 \\
\hline$v_{\text {sy }}(\mathrm{N}-\mathrm{H})$ & & & & & & 3263 & 3254 & & \\
\hline$\nu_{\mathrm{as}}(\mathrm{COO})$ & & 1590 & 1640 & & & 1669 & 1672 & 1667 & 1667 \\
\hline$v_{\text {sy }}(\mathrm{COO})$ & & 1480 & 1492 & & & 1449 & 1466 & 1467 & 1442 \\
\hline$\nu(\mathrm{C}-\mathrm{N})$ & & & & 1341 & 1552 & 1275 & 1380 & 1330 & 1308 \\
\hline$v(\mathrm{M}-\mathrm{N})$ & & & & & & 563 & 565 & 562 & 557 \\
\hline$\nu(\mathrm{M}-\mathrm{O})$ & & & & 637 & 621 & 618 & 655 & 680 & 604 \\
\hline
\end{tabular}

on similar compounds [9]. In the spectrum of hnc the $\mathrm{OH}$ stretching frequency was observed as an intense broad band at $3435 \mathrm{~cm}^{-1}$. This was however absent in the spectra of the complexes, suggesting the deprotonation of the hydroxy group. This is in accord with that observed in previous reports $[9,48]$. The spectrum of hnc also exhibited a broad band at $2892 \mathrm{~cm}^{-1}$, attributable to intramolecular hydrogen bonded $-\mathrm{OH}[47,49,50]$. This band disappeared in the spectra of the coordination compounds, indicating the breakdown of hydrogen-bonding and subsequent deprotonation of the $\mathrm{OH}$ group prior to coordination of the resultant oxygen anion. This was further corroborated by the observed shifts in the $v(\mathrm{C}-\mathrm{O})$ (alcoholic) stretch of hnc at $1009 \mathrm{~cm}^{-1}$ to higher energy by 48 and $62 \mathrm{~cm}^{-1}$ in the coordination compounds of 1 and 2 , respectively $[47,49,50]$. A weak broad band however was observed within the range $3468 \mathrm{~cm}^{-1}$ in the spectra of 1 and $\mathbf{2}$ and is suggestive of the involvement of the oxygen atom of water in coordination $[49,50]$. The appearance of a new medium intense band at $1135 \mathrm{~cm}^{-1}$ which is a characteristic bending vibration of coordinated water molecule, $\delta(\mathrm{M}-\mathrm{O}-$ $\mathrm{H})$, further confirmed this [50].

There were significant shifts in the $(\mathrm{C}=\mathrm{O})$ stretching frequency which lowered upon complexation for complexes 1 and 2 (Table 1) compared to that of the ligand. Previous reports have taken similar shifts as evidence of coordination via the carbonyl oxygen. However, more recent studies have suggested that this is not so. It was pointed out that such shifts may be as a result of the carbonyl being located on the same lactone ring as the ligand binding sites in the complexes [9, $10]$. New bands absent in that of the ligand were observed at 637 and $621 \mathrm{~cm}^{-1}$ (Table 1), which were assigned as stretching frequencies of metal-oxygen bonds $[48,50,51]$.

3.1.2. Compounds 3 and 4. The infrared spectra of the mixed ligand species of $\mathbf{3}$ and $\mathbf{4}$ provided evidence of coordination of hnc to the corresponding metal(II) ions. Such evidence was demonstrated by the shifts in the $-\mathrm{NO}_{2}$ asymmetric stretching frequency, observed at $1522 \mathrm{~cm}^{-1}$ in the free ligand but which shifted to higher frequencies in 3 and 4 (Table 1), thus indicative of coordination of an oxygen atom of the nitro group $[8,10]$. The deprotonation and subsequent involvement of the oxygen atom in coordination was indicated by the disappearance of the band at $3435 \mathrm{~cm}^{-1}$ in hnc in the spectra of the complexes. A new weak and broad band at $3446 \mathrm{~cm}^{-1}$ assignable to $\nu(\mathrm{O}-\mathrm{H})$ frequency suggested coordination via the oxygen of water molecule. This was confirmed by the observance of $\delta(\mathrm{M}-\mathrm{O}-\mathrm{H})$ frequencies at 1125 and $1202 \mathrm{~cm}^{-1}$ for compounds 3 and $\mathbf{4}[48,50]$.

The infrared spectrum of uncoordinated $\mathbf{L}^{\prime}$ exhibited $v(\mathrm{~N}-\mathrm{H})$ stretching frequency at $3196 \mathrm{~cm}^{-1}$. The spectra of compounds 3 and 4 both exhibited bands at 3301, 3263, 3374 , and $3254 \mathrm{~cm}^{-1}$, respectively, assigned to $v_{\text {asy }}(\mathrm{N}-\mathrm{H})$ and $v_{\text {sy }}(\mathrm{N}-\mathrm{H})$ stretching frequencies and indicative of the involvement of nitrogen atom of its amino substituent in coordination of the metal ion with the ligand [50]. It should be noted that complexes 1 and $\mathbf{2}$ did not exhibit this stretching frequencies in comparison. The appearance of new bands, which were not present in the spectrum of the ligands, at 501 and $509 \mathrm{~cm}^{-1}$ ascribable to metal-nitrogen absorption frequencies of $\mathbf{3}$ and $\mathbf{4}$, respectively, further confirmed this $[48,52]$. The observed medium band at $1112 \mathrm{~cm}^{-1}$ in the free ligand was attributed to the $\nu(\mathrm{C}-\mathrm{N})$ absorption frequency and this blue shifted on coordination in the complexes [50]. The spectrum of $\mathbf{L}^{\prime}$ also exhibited bands at 1590 and $1480 \mathrm{~cm}^{-1}$ ascribed as $v_{\text {asy }}(\mathrm{COO})$ and $v_{\text {sy }}(\mathrm{COO})$ stretching frequencies, respectively [50]. The shifts in $\nu_{\text {asy }}(\mathrm{COO})$ absorption to 1669 and $1672 \mathrm{~cm}^{-1}$ for 3 and 4, respectively, and that for $v_{\text {sy }}(\mathrm{COO})$ stretch to 1449 and $1466 \mathrm{~cm}^{-1}$ are indicative of the coordination of the oxygen atom of the carboxylate group in the coordination compounds $[16,44,50,53]$. The hypsochromic shifts in the $v_{\text {asy }}(\mathrm{COO})$ frequency and bathochromic shifts for the $v_{\text {sy }}(\mathrm{COO})$ frequency for compounds $\mathbf{3}$ and $\mathbf{4}$ indicated the 
monodenticity of the carboxylate ion on coordination. This is in agreement with established reports and was confirmed by the observed energy difference $(\Delta v=200-225)$ between both asymmetric and symmetric stretches in the coordination compounds $[16,17,50,54]$. New bands that were absent in the ligand but present in that of the complexes at 618 and $655 \mathrm{~cm}^{-1}$ (Table 1) were attributed to the $\mathrm{M}-\mathrm{O}$ stretching frequencies $[44,48,50]$.

3.1.3. Compounds 5 and 6. Similar to that obtained for complexes 1-4, the infrared spectrum for complex 5 suggested coordination via an oxygen atom of $-\mathrm{NO}_{2}$ of hnc; this is due to the observed shift in the $-\mathrm{NO}_{2}$ asymmetric stretching frequency in comparison to that displayed by the free ligand hnc. However in the spectrum of compound $\mathbf{6}$ this absorption band was not observed; it is suggested to be as a result of overlap of the $v_{\text {asy }}(\mathrm{COO}), v_{\text {sy }}(\mathrm{COO}), v(\mathrm{C}=\mathrm{C})$, and $v(\mathrm{C}=\mathrm{O})$ absorption bands which all lie within the region close to that expected for the $-\mathrm{NO}_{2}$ asymmetric stretch [50]. Both spectra of compounds 5 and $\mathbf{6}$ however exhibited broad bands within the region $3444 \mathrm{~cm}^{-1}$; this in comparison with the observed band at $3435 \mathrm{~cm}^{-1}$ in the spectrum of hnc also suggests the deprotonation of the $-\mathrm{OH}$ with probable coordination of water molecule. The $(\mathrm{C}-\mathrm{O})$ stretching frequency was observed at 1068 and $1045 \mathrm{~cm}^{-1}$.

In the case of pyrrolidine-2-carboxylic acid $\nu(\mathrm{N}-\mathrm{H})$ was observed as a single band at $3152 \mathrm{~cm}^{-1}$ in its spectrum. This was shifted hypsochromically to 3233 and $3510 \mathrm{~cm}^{-1}$ for 5 and 6 on complexation $[47,55]$, thus indicating coordination via the nitrogen of the amino substituent on coordination. Supporting this further is the observed shifts to higher wave number for the $v(\mathrm{C}-\mathrm{N})$ stretching frequency (Table 1 ). This was corroborated by the appearance of $\mathrm{M}-\mathrm{N}$ band observed at 562 and $557 \mathrm{~cm}^{-1}$ for compounds 5 and 6, respectively, which was absent in both ligands. The observed strong band at $1640 \mathrm{~cm}^{-1}$ in the free ligand $\mathrm{L}^{\prime \prime}$ was attributed to the $v_{\text {asy }}(\mathrm{COO})$ absorption and this blue shifted on coordination in both complexes [50]. The $v_{\text {sy }}(\mathrm{COO})$ band at $1492 \mathrm{~cm}^{-1}$ in the free ligand $\mathbf{L}^{\prime \prime}$ gave bathochromic shifts in that of the complexes. These shifts are similar to that obtained for compounds $\mathbf{3}$ and $\mathbf{4}$ and suggest the monodentate nature of the carboxylate moiety in coordination. The observed energy difference between both asymmetric and symmetric stretches in the coordination compounds (Table 1) corroborates this further $[16,17,50,54]$. In addition, new bands were observed at 680 and $604 \mathrm{~cm}^{-1}$ and were assigned as metal-oxygen stretching frequencies for compounds $\mathbf{5}$ and $\mathbf{6}$, respectively [50].

3.2. Electronic Spectra and Magnetic Moment. The electronic spectrum for the free ligand, $\mathbf{L}^{\prime}$, exhibited bands at 199, 230, and $331 \mathrm{~nm}$ attributed as $n \rightarrow \sigma^{*}, n \rightarrow \pi^{*}$, and $\pi^{*} \rightarrow$ $\pi^{*}$ transitions $[47,49]$. Similarly the spectrum of $\mathbf{L}^{\prime \prime}$ also exhibited bands at 197 and $234 \mathrm{~nm}$, ascribed to $n \rightarrow \sigma^{*}$ and $n \rightarrow \pi^{*}$ transitions. For the free ligand 4-hydroxy-3-nitro$2 \mathrm{H}$-chromen-2-one intense absorption bands at 205, 220, 297, and $410 \mathrm{~nm}$ were observed which were assigned as $n \rightarrow \sigma^{*}$, $n \rightarrow \pi^{*}$, and $\pi^{*} \rightarrow \pi^{*}$ transitions. These transitions are
TABLE 2: Electronic spectra bands ( $\mathrm{nm}$ ) for the ligands and complexes.

\begin{tabular}{lcccccc}
\hline Compounds & $\mathbf{1}$ & $\mathbf{2}$ & $\mathbf{3}$ & $\mathbf{4}$ & $\mathrm{d}-\mathrm{d}$ & $\boldsymbol{\mu}_{\mathrm{eff}}$ \\
& & & Bands $(\mathrm{nm})$ & & & \\
\hline Hnc & 205 & 220 & 297 & 410 & & \\
$\mathbf{L}^{\prime}$ & 199 & 230 & 331 & & & \\
$\mathbf{L}^{\prime \prime}$ & 197 & 234 & & & & \\
$\mathbf{1}$ & & & & 392 & 548,632 & 2.6 \\
$\mathbf{2}$ & & & & 460 & - & \\
$\mathbf{3}$ & & & & 370 & 668,720 & 1.53 \\
$\mathbf{4}$ & & & & 480 & - & 0 \\
$\mathbf{5}$ & & & & 370 & 670 & 1.42 \\
$\mathbf{6}$ & & & & 484 & - & 0 \\
\hline
\end{tabular}

ascribable to the major chromophore systems of the ligands. Shifts in these bands and the observed d-d transitions are presented in Table 2.

The electronic spectrum of compound 1 exhibited a well resolved band at $548 \mathrm{~nm}$ and a weak band at $632 \mathrm{~nm}$ assignable to ${ }^{2} \mathrm{~B}_{1 \mathrm{~g}} \rightarrow{ }^{2} \mathrm{~A}_{\mathrm{lg}}$ and ${ }^{2} \mathrm{~B}_{1 \mathrm{~g}} \rightarrow{ }^{2} \mathrm{E}_{\mathrm{g}}$ transitions, which suggested an octahedral geometry $[32,56]$. This proposed geometry was corroborated by its magnetic moment of 2.60 BM, indicative of a tetragonally distorted octahedral geometry $[28,40]$. This is in agreement with that proposed by previous workers for similar compounds $[9,57,58]$. Intraligand transitions were observed at 215, 281, and $392 \mathrm{~nm}$. The spectrum of 2 exhibited a band at $705 \mathrm{~nm}$ ascribed to charge transfer band. No d-d absorption band was observed in the visible region for compound 2. A magnetic moment of zero was obtained, indicating that there was no unpaired electron for the metal ion. This is in accord with that obtained by previous workers on $\mathrm{Zn}$ (II) complexes [55, 56, 59].

The visible spectrum of compound 3 displayed broad band at 668 and $720 \mathrm{~nm}$ assigned to ${ }^{2} \mathrm{~B}_{1 \mathrm{~g}} \rightarrow{ }^{2} \mathrm{~A}_{\mathrm{lg}}$ and ${ }^{2} \mathrm{~B}_{1 \mathrm{~g}} \rightarrow{ }^{2} \mathrm{E}_{\mathrm{lg}}$ transitions. Its magnetic moment of $1.53 \mathrm{BM}$ is indicative of an antiferromagnetic spin-spin interaction through molecular association with possible $\mathrm{Cu}-\mathrm{Cu}$ interaction or dimerization [55]. However a dimerized geometry is proposed based on the molecular ion obtained from its mass spectrum. Similar results have been published for coordination compounds of amino acids and coumarins [18, 41]. The intraligand transition was observed at $370 \mathrm{~nm}$. The spectrum of 4 exhibited no band in the visible region of the spectrum. This is partly due to the fully filled $3 \mathrm{~d}$ of $\mathrm{Zn}$ (II) ion. Its magnetic moment of zero corroborated this further. Intraligand transition band was observed at $480 \mathrm{~nm}$ for this compound. An octahedral geometry is however proposed for this complex and is consistent with results obtained for the metal analysis using EDX and EDTA complexometric titration (cal.: 17.06; found: 16.84).

The visible spectrum of compound 5 exhibited a broad band at $670 \mathrm{~nm}$ assignable to ${ }^{2} \mathrm{~B}_{1 \mathrm{~g}} \rightarrow{ }^{2} \mathrm{~A}_{\mathrm{lg}}$ transition and a shoulder at $723 \mathrm{~nm}$ assigned as ${ }^{2} \mathrm{~B}_{1 \mathrm{~g}} \rightarrow{ }^{2} \mathrm{E}_{\mathrm{lg}}$ transition. Its magnetic moment of $1.42 \mathrm{BM}$ is suggestive of dimerization [55]. Intraligand transition was observed as an intense band 
<smiles>O=c1oc2ccccc2c([W](O)(O)O[N+]([O-])(O)c2c([N+](=O)[O-])c3ccccc3oc2=O)c1[N+](=O)[O-]</smiles>

FIGURE 2: Proposed structure for compounds 1 and 2.

at $370 \mathrm{~nm}$. The spectrum of 6 exhibited no band in the visible region of the spectrum. Its magnetic moment of zero corroborated this further. Its intraligand transition band was observed at $484 \mathrm{~nm}$. An octahedral geometry is proposed for this complex and is supported by results obtained for the metal analysis using EDX for qualitative and EDTA complexometric titration for quantitative analysis (cal.: 15.44; found: 14.57).

Based on the results obtained it is suggested that compounds $\mathbf{1}$ and $\mathbf{2}$ exhibited octahedral geometry comprising two hnc ligands coordinating in a bidentate fashion and two monodentate water ligands. It is proposed that the two hnc ligands are coordinated to the metal ion via the deprotonated hydroxo moiety and an oxygen atom of the nitro group $[9,17,18,60,61]$. This result is in agreement with that obtained by Creaven et al., 2005, for similar compounds [9]. Hence the structure shown in Figure 2 is proposed for these complexes.

In the case of compounds $\mathbf{3}$ and $\mathbf{5}$ the results obtained indicated that coordination occurred via an oxygen atom of the nitro group and the oxygen of deprotonated hydroxo substituent in hnc $[9,17,18,60,61]$. However the carbonyl of hnc is proposed to coordinate with neighbouring metal ion leading to dimerization. For the amino acid, however, coordination is suggested to occur via the amino nitrogen and an oxygen atom of the carboxylate ion. According to Nakamoto, 2009, it has been shown that the oxygen atoms of the carbonyl groups which are not coordinated to the central metal ion are hydrogen bonded either to the amino group of the neighbouring molecule or to water of crystallization or are bound weakly to the metal of the neighbouring complex. It is proposed that in $\mathbf{3}$ and $\mathbf{5}$ such carbonyl groups are weakly bound to the metal of the neighbouring complex [50,62]. As a result the structure as shown in Figure 3 is suggested for the complexes. This was corroborated by the observed parent molecular ion $\mathrm{M}^{+\bullet}$, obtained from the mass spectrum of compound 3 , and is consistent with the expected molecular formula for the proposed structure.

For compounds $\mathbf{4}$ and $\mathbf{6}$ the results obtained suggested an octahedral geometry; it is proposed that coordination occurred via one of the nitro $\mathrm{O}$ - atoms and the deprotonated oxygen in hnc. However, the amino acids coordination occurred via the amino $\mathrm{N}$ - and one of the carboxylato $\mathrm{O}-$ atoms. As a result a representation of the proposed structure of the complexes is given in Figure 4.

These results further affirmed the coordination behaviour of hnc as a function of the $\mathrm{pH}$ of the reaction. This is

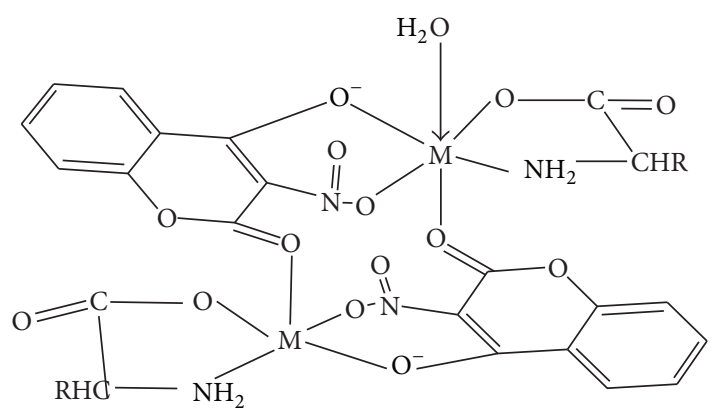

FIgURE 3: Proposed structure for compounds $\mathbf{3}$ and $\mathbf{5}$. $\mathbf{R}=-\mathrm{H}$, compound 3, and $-\mathrm{C}_{4} \mathrm{H}_{8}$, compound 5 .

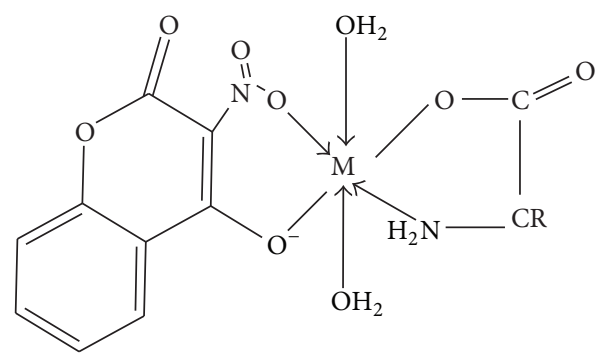

Figure 4: Proposed structure for compounds 4 and $\mathbf{6}$. $R=-H$, compound 4, and $-\mathrm{C}_{4} \mathrm{H}_{8}$, compound 6 .

suggested by the deprotonation of hydroxo group in alkaline medium contrary to that obtained by previous reports for less basic media $[9,10,18]$. The results obtained also validated previous report on the enhanced individuality of the central metal ions in the mixed ligand complexes [19].

3.3. Antimicrobial. A comparative evaluation of the antimicrobial activity of hnc, $\mathbf{L}^{\prime}, \mathbf{L}^{\prime \prime}$, and the synthesized compounds 1-6 was carried out against five Gram-positive bacteria, three Gram-negative bacteria, and two fungi. The results obtained are presented in Table 3 . The result indicated that $\mathbf{L}^{\prime}$ and $\mathbf{L}^{\prime \prime}$ were both inactive to all the tested organisms. On the other hand hnc exhibited weak activity against $K$. pneumoniae. Both standards (imipenem for bacteria and chlorhexidine for fungi) exhibited significantly better activity than all the synthesized compounds and ligands $(P<0.05)$. Only three of the compounds demonstrated antimicrobial action and this activity was shown against only $S$. aureus and K. pneumoniae, Table 3. Compounds 2, 3, and 4 exhibited good activity against $S$. aureus, a Gram-positive bacteria, suggesting the enhanced lipophilicity of the complexes on coordination [27, 28, 30, 63]. Compounds 2 and $\mathbf{3}$ exhibited activity against $K$. pneumonia. It would have been expected that the $\mathbf{L}^{\prime \prime}$ adducts should be more active against Grampositive bacteria, as a result of the nonpolar side chain of $\mathbf{L}^{\prime \prime}$ with plausible enhanced lipophilicity of the complexes relative to that of $\mathbf{L}^{\prime}$, but this was not so $[27,28,30,63]$. The reason for this is not quite evident. This therefore serves as an indication that activity does not depend solely on the ease of movement of an antimicrobial agent through the cell wall of 
TABLE 3: Result of zone of antimicrobial inhibition ( $\mathrm{mm})$ for the ligands and complexes.

\begin{tabular}{|c|c|c|c|c|c|c|c|c|c|c|}
\hline & hnc & $\mathrm{L}^{\prime}$ & $\mathrm{L}^{\prime \prime}$ & 1 & 2 & 3 & 4 & 5 & 6 & $\mathrm{C}$ \\
\hline S. aureus & - & - & - & - & 09 & - & 17 & - & - & 44 \\
\hline S. epidermidis & - & - & - & - & - & - & - & - & - & 34 \\
\hline B. subtilis 12 & - & - & - & - & - & - & - & - & - & 34 \\
\hline B. subtilis 82 & - & - & - & - & - & - & - & - & - & 29 \\
\hline Clostridium & - & - & - & - & - & - & - & - & - & 34 \\
\hline K. pneumoniae & 09 & - & - & - & - & 07 & 08 & - & - & 34 \\
\hline P. aeruginosa & - & - & - & - & - & - & - & - & - & 39 \\
\hline E. coli & - & - & - & - & - & - & - & - & - & 33 \\
\hline C. albicans & - & - & - & - & - & - & - & - & - & 36 \\
\hline C. pseudotropicalis & - & - & - & - & - & - & 09 & - & - & 36 \\
\hline
\end{tabular}

$\mathrm{C}$ means imipenem and chlorhexidine for bacteria and fungi, respectively.

the microbes, but rather a synergistic effects of many factors [64-66].

3.4. Cytotoxicity. Brine shrimp lethality assay of the synthesized compounds and ligands was carried out, and the result obtained indicated that hnc $\left(\mathrm{LC}_{50} 7.56 \mu \mathrm{g} / \mathrm{ml}\right)$ was the most active of the ligands. This was followed by $\mathrm{L}^{\prime}\left(\mathrm{LC}_{50}\right.$ $8.01 \mu \mathrm{g} / \mathrm{ml})$ and $\mathbf{L}^{\prime \prime}\left(\mathrm{LC}_{50} 11.96 \mu \mathrm{g} / \mathrm{ml}\right)$. The order of activity of the compounds is as follows: compound $\mathbf{2}>\mathbf{1}>\mathbf{5}>\mathbf{3}>\mathbf{4}>$ 6, with $\mathrm{LC}_{50} 11.56,12.00,12.68,12.93,16.49$, and $35.91 \mu \mathrm{g} / \mathrm{ml}$, respectively. The standard $\mathrm{K}_{2} \mathrm{Cr}_{2} \mathrm{O}_{7}\left(\mathrm{LC}_{50} 5.56 \mu \mathrm{g} / \mathrm{ml}\right)$ however exhibited significantly higher $(P<0.05)$ cytotoxic activity compared with that of the ligands and synthesized compounds. The synthesized compounds on the other hand exhibited significantly better activity relative to their metal salts, namely, zinc(II) chloride ( $\left.\mathrm{LC}_{50} 88.89 \mu \mathrm{g} / \mathrm{ml}\right)$ and copper(II) chloride dihydrate $\left(\mathrm{LC}_{50} 98.34 \mu \mathrm{g} / \mathrm{ml}\right)$. Similar results have been reported for cerium coumarin complexes [25]. The ternary hnc complexes had comparable activity in some cases relative to their mixed ligand counterparts. Thus indicating that the formation of adducts did not enhance the cytotoxic activity of the ternary hnc complexes. This may be attributed to the fact that the amino acids had lesser activity than hnc. The results obtained indicated that the $\operatorname{zinc}(\mathrm{II})$ complexes were more active than the copper(II) complexes of similar species with the exception of the pyrrolidine-2-carboxylic acid adduct. This may be ascribed to the size of the metal ion, the better activity of the metal salt, and more importantly the structure of the compounds. The activity of the pyrrolidine2 -carboxylic acid adduct of zinc, compound $\mathbf{6}$, suggests the nontoxic nature of the complex $[67,68]$. The results suggest therefore that although chelation may not enhance the brine shrimp lethality ability of the synthesized compounds, it should be noted that it however enhanced the nontoxic nature of the ligands. Moreover, the cytotoxicity of the metal salts increased on chelation.

\section{Conclusion}

It was concluded from the study that the available coordinating species in 4-hydroxy-3-nitro- $2 \mathrm{H}$-chromen-2-one is a function of the $\mathrm{pH}$ of the reaction. In addition the enhanced individuality of the central metal ion in mixed ligand complexes was also demonstrated in the study. It was further concluded that although chelation may enhance the bioavailability of coordination compounds as therapeutic agents; however other factors also play important roles for their effectiveness.

\section{Competing Interests}

The authors declare that there are no competing interests regarding the publication of this paper.

\section{References}

[1] S. S. Bahekar and D. B. Shinde, "Samarium(III) catalyzed onepot construction of coumarins," Tetrahedron Letters, vol. 45, no. 43, pp. 7999-8001, 2004.

[2] A. A. Emmanuel-Giota and K. C. Fylaktakidou, "Synthesis and biological evaluation of several 3-(coumarin-4yl)tetrahydroisoxazole and 3-(coumarin-4-yl)dihydropyrazole derivatives," Journal of Heterocyclic Chemistry, vol. 38, no. 3, pp. 717-722, 2001.

[3] A. M. El-Sayed and O. A. Abd Allah, "Synthetic and biological studies on coumarin hydrazone derivatives," Phosphorus, Sulfur and Silicon and Related Elements, vol. 170, pp. 75-86, 2001.

[4] L. D. Raev, E. Voinova, I. C. Ivanov, and D. Popov, "Antitumor activity of some coumarin derivatives," Pharmazie, vol. 45, no. 9, p. 696, 1990.

[5] A. Karaliota, O. Kretsi, and C. Tzougraki, "Synthesis and characterization of a binuclear coumarin-3-carboxylate copper(II) complex," Journal of Inorganic Biochemistry, vol. 84, no. 1-2, pp. 33-37, 2001.

[6] D. Egan, R. O’Kennedy, E. Moran, D. Cox, E. Prosser, and R. D. Thornes, "The pharmacology, metabolism, analysis, and applications of coumarin and coumarin-related compounds," Drug Metabolism Reviews, vol. 22, no. 5, pp. 503-529, 1990.

[7] C. Gnerre, M. Catto, F. Leonetti et al., "Inhibition of monoamine oxidases by functionalized coumarin derivatives: biological activities, QSARs, and 3D-QSARs," Journal of Medicinal Chemistry, vol. 43, no. 25, pp. 4747-4758, 2000.

[8] J. A. Kumar, G. Saidachary, G. Mallesham et al., "Synthesis, anticancer activity and photophysical properties of novel substituted 2-oxo-2H-chromenylpyrazolecarboxylates," European Journal of Medicinal Chemistry, vol. 65, pp. 389-402, 2013. 
[9] B. S. Creaven, D. A. Egan, K. Kavanagh et al., "Synthesis and antimicrobial activity of copper(II) and silver(I) complexes of hydroxynitrocoumarins: X-ray crystal structures of $\left[\mathrm{Cu}(\mathrm{hnc})_{2}\left(\mathrm{H}_{2} \mathrm{O}\right)_{2}\right] \cdot 2 \mathrm{H}_{2} \mathrm{O}$ and $[\mathrm{Ag}(\mathrm{hnc})](\mathrm{hncH}=4$-hydroxy3-nitro-2H-chromen-2-one)," Polyhedron, vol. 24, no. 8, pp. 949-957, 2005.

[10] B. B. Kumaar, V. J. Kumar, V. Raju, Ranabaore, and M. C. Ganorkar, Oriental Journal of Chemistry, vol. 3, p. 34, 1987.

[11] D. Subhas Bose, A. P. Rudradas, and M. Hari Babu, "The indium(III) chloride-catalyzed von Pechmann reaction: a simple and effective procedure for the synthesis of 4-substituted coumarins," Tetrahedron Letters, vol. 43, no. 50, pp. 9195-9197, 2002.

[12] R. O'Kennedy and R. D. Thornes, Coumarins: Biology, Applications and Mode of Action, John Wiley \& Sons, Chichester, UK, 1997.

[13] M. K. Potdar, S. S. Mohile, and M. M. Salunkhe, "Coumarin syntheses via Pechmann condensation in Lewis acidic chloroaluminate ionic liquid," Tetrahedron Letters, vol. 42, no. 52, pp. 9285-9287, 2001.

[14] M. Zahradnik, The Production and Application of Fluorescent Brightening Agent, John Wiley \& Sons, Chichester, UK, 1992.

[15] B. R. Dekić, N. S. Radulović, V. S. Dekić, R. D. Vukicević, and R. M. Palić, "Synthesis and antimicrobial activity of new 4heteroarylamino coumarin derivatives containing nitrogen and sulfur as heteroatoms," Molecules, vol. 15, no. 4, pp. 2246-2256, 2010.

[16] N. Sultana, A. Naz, M. S. Arayne, and M. A. Mesaik, "Synthesis, characterization, antibacterial, antifungal and immunomodulating activities of gatifloxacin-metal complexes," Journal of Molecular Structure, vol. 969, no. 1-3, pp. 17-24, 2010.

[17] A. Mishra, J. Rathod, D. Namera, S. Thakrar, and A. Shah, "Synthesis and antimicrobial activity of coumarinyl schiff base derivatives," International Letters of Chemistry, Physics and Astronomy, vol. 30, pp. 193-201, 2014.

[18] I. Kostova, G. Momekov, M. Zaharieva, and M. Karaivanova, "Cytotoxic activity of new lanthanum (III) complexes of biscoumarins," European Journal of Medicinal Chemistry, vol. 40, no. 6, pp. 542-551, 2005.

[19] I. P. Alimarin and I. Shlenskaya, The Analytical Chemistry of Mixed Ligand Complexes 463 Institute of Analytical Chemistry, M. V. Lomonosov Moscow State University, U.S.S.R, Moscow, Russia, 1970.

[20] H. C. Freeman, "Metal complexes of amino acid and peptides," in Inorganic Biochemistry, G. Eichhorn, Ed., pp. 121-150, Elsevier, London, UK, 1973.

[21] M. N. Hughes, "Coordination compounds in biology," in Comprehensive Coordination Chemistry, G. Wilkonson, R. D. Gillard, and J. A. McCleverty, Eds., vol. 6, pp. 541-754, Pergamon Press, Oxford, UK, 1987.

[22] J. L. Aull, H. H. Daron, M. E. Friedman, and P. Melius, Interactions of Anticancer Drugs with Enzymes Metal Ion in the Biological System, Edited by H. Sigel, Marcel Dekker, New York, NY, USA, 1980.

[23] V. S. Shivankar, R. B. Vaidya, S. R. Dharwadkar, and N. V. Thakkar, "Synthesis, characterization, and biological activity of mixed ligand $\mathrm{Co}$ (II) complexes of 8-hydroxyquinoline and some amino acids," Synthesis and Reactivity in Inorganic and Metal-Organic Chemistry, vol. 33, no. 9, pp. 1597-1622, 2003.

[24] A. Adkhis, O. Benali-Baïtich, M. A. Khan, and G. Bouet, "Synthesis, characterization and thermal behaviour of mixedligand complexes of cobalt(III) with dimethylglyoxime and some amino acids," Synthesis and Reactivity in Inorganic and Metal-Organic Chemistry, vol. 30, no. 10, pp. 1849-1858, 2000.

[25] I. Manolov, I. Kostova, T. Netzeva, S. Konstantinov, and M. Karaivanova, "Cytotoxic activity of cerium complexes with coumarin derivatives. Molecular modeling of the ligands," Archiv der Pharmazie, vol. 333, no. 4, pp. 93-98, 2000.

[26] H. Sakurai, Y. Kojima, Y. Yoshikawa, K. Kawabe, and H. Yasui, "Antidiabetic vanadium(IV) and zinc(II) complexes," Coordination Chemistry Reviews, vol. 226, no. 1-2, pp. 187-198, 2002.

[27] E. L. Chang, C. Simmers, and D. A. Knight, "Cobalt complexes as antiviral and antibacterial agents," Pharmaceuticals, vol. 3, no. 6, pp. 1711-1728, 2010.

[28] Z. H. Chohan, M. Arif, M. A. Akhtar, and C. T. Supuran, "Metal-based antibacterial and antifungal agents: synthesis, characterization, and in vitro biological evaluation of $\mathrm{Co}$ (II), $\mathrm{Cu}(\mathrm{II}), \mathrm{Ni}(\mathrm{II})$, and $\mathrm{Zn}$ (II) complexes with amino acid-derived compounds," Bioinorganic Chemistry and Applications, vol. 2006, Article ID 83131, 13 pages, 2006.

[29] P. Sadlers, C. Muncia, and M. A. Shipman, "Metals in medicine," in Biological Inorganic Chemistry: Structure and Reactivity, I. Bertini, H. Gray, E. Stiefel, and J. Valentine, Eds., pp. 115-136, University Science Books, London, UK, 2007.

[30] Z. H. Chohan, M. A. Farooq, A. Scozzafava, and C. T. Supuran, "Antibacterial schiff bases of oxalyl-hydrazine/diamide incorporating pyrrolyl and salicylyl moieties and of their zinc(II) complexes," Journal of Enzyme Inhibition and Medicinal Chemistry, vol. 17, no. 1, pp. 1-7, 2002.

[31] C. X. Zhang and S. J. Lippard, "New metal complexes as potential therapeutics," Current Opinion in Chemical Biology, vol. 7, no. 4, pp. 481-489, 2003.

[32] S. Emami and S. Dadashpour, "Current developments of coumarin-based anti-cancer agents in medicinal chemistry," European Journal of Medicinal Chemistry, vol. 102, pp. 611-630, 2015.

[33] I. Georgieva, T. Mihaylov, and N. Trendafilova, "Lanthanide and transition metal complexes of bioactive coumarins: molecular modeling and spectroscopic studies," Journal of Inorganic Biochemistry, vol. 135, pp. 100-112, 2014.

[34] I. S. Butler, D. F. R. Gilson, B. J. Jean-Claude, and S. I. Mostafa, "Synthesis of new 4-methylesculetin complexes as anti-neoplastic agents and X-ray structure of dimeric bisbipyridyl-bis-4-methylesculetinato zinc(II)," Inorganica Chimica Acta, vol. 423, pp. 132-143, 2014.

[35] D. R. Ilić, V. V. Jevtić, G. P. Radić et al., "Synthesis, characterization and cytotoxicity of a new palladium(II) complex with a coumarine-derived ligand," European Journal of Medicinal Chemistry, vol. 74, pp. 502-508, 2014.

[36] B. Thati, A. Noble, B. S. Creaven, M. Walsh, K. Kavanagh, and D. A. Egan, "Apoptotic cell death: a possible key event in mediating the in vitro anti-proliferative effect of a novel copper(II) complex, [Cu(4-Mecdoa)(phen) $)_{2}$ (phen = phenanthroline, 4-Mecdoa = 4-methylcoumarin-6,7-dioxactetate), in human malignant cancer cell," European Journal of Pharmacology, vol. 569, no. 1-2, pp. 16-28, 2007.

[37] I. Kostova, G. Momekov, and P. Stancheva, "New samarium(III), gadolinium(III), and dysprosium(III) complexes of coumarin-3-carboxylic acid as antiproliferative agents," MetalBased Drugs, vol. 2007, Article ID 15925, 8 pages, 2007. 
[38] I. Kostova, G. Momekov, T. Tzanova, and M. Karaivanova, "Synthesis, characterization, and cytotoxic activity of new lanthanum(III) complexes of bis-coumarins," Bioinorganic Chemistry and Applications, vol. 2006, Article ID 25651, 9 pages, 2006.

[39] S. Saha, D. Dhanasekaran, S. Chandraleka, N. Thajuddin, and A. Panneerselvam, "Synthesis, characterization and antimicrobial activity of cobalt metal complexes against drug resistant bacterial and fungal pathogens," Advances in Biological Research, vol. 4, pp. 224-229, 2010.

[40] T. O. Aiyelabola, I. A. Ojo, A. C. Adebajo et al., "Synthesis, characterization and antimicrobial activities of some metal(II) amino acids' complexes," Advances in Biological Chemistry, vol. 2, no. 3, pp. 268-273, 2012.

[41] K. Bukietyńska, H. Podsiadły, and Z. Karwecka, "Complexes of vanadium(III) with L-alanine and L-aspartic acid," Journal of Inorganic Biochemistry, vol. 94, no. 4, pp. 317-325, 2003.

[42] K. Nomiya and H. Yokoyama, "Syntheses, crystal structures and antimicrobial activities of polymeric silver(I) complexes with three amino-acids [aspartic acid $\left(\mathrm{H}_{2}\right.$ asp), glycine (Hgly) and asparagine (Hasn)]," Journal of the Chemical Society, Dalton Transactions, no. 12, pp. 2483-2490, 2002.

[43] A. Legler, A. Kazachenko, V. Kazbanov, and O. Pery'anova, "Synthesis and antimicrobial activity of silver complexes with arginine and glutamic acid," Pharmaceutical Chemistry, vol. 35, no. 1, pp. 35-36, 2001.

[44] Y. Hui, H. Qizhuang, Z. Meifeng, X. Yanming, and S. Jingyi, "Synthesis, characterization and biological activity of rare earth complexes with L-aspartic acid and o-phenanthroline," Journal of the Chinese Rare Earth Society, vol. 2, pp. 3-4, 2007.

[45] T. O. Aiyelabola, I. A. O. Ojo, and E. O. Akinkunmi, "Structural and antimicrobial studies of coordination compounds of phenylalanine and glycine," International Journal of Chemistry (Canada), vol. 4, no. 7, pp. 1-11, 2012.

[46] P. N. Solis, C. W. Wright, M. M. Anderson, M. P. Gupta, and J. D. Phillipson, "A microwell cytotoxicity assay using Artemia salina (brine shrimp)," Planta Medica, vol. 59, no. 3, pp. 250-252, 1993.

[47] W. Kemp, "Infrared spectroscopy," in Organic Spectroscopy, pp. 22-38, Macmillan, Hong Kong, 1991.

[48] A. A. Osowole, G. A. Kolawole, and O. E. Fagade, "Synthesis, characterization and biological studies on unsymmetrical Schiff-base complexes of nickel(II), copper(II) and zinc(II) and adducts with 2,2I-dipyridine and 1,10-phenanthroline," Journal of Coordination Chemistry, vol. 61, no. 7, pp. 1046-1055, 2008.

[49] D. Pavia, G. Lampman, and G. Kriz, "Introduction to spectroscopy," in A Guide for Students of Organic Chemistry, pp. 22368, Brooks and Cole, New York, NY, USA, 3rd edition, 2001.

[50] K. Nakamoto, "Complexes of amino acids," in Infraredd and Raman Spectroscopy of Inorganic and Coordination Compounds: Applications in Coordination, Organometallics and Bioinorganic Chemistry, pp. 67-69, John Wiley and Sons, New York, NY, USA, 6th edition, 2009.

[51] A. S. Gaballa, S. M. Teleb, M. S. Asker, E. Yalçin, and Z. Seferoğlu, "Synthesis, spectroscopic properties, and antimicrobial activity of some new 5-phenylazo-6-aminouracil-vanadyl complexes," Journal of Coordination Chemistry, vol. 64, no. 24, pp. 4225-4243, 2011.

[52] A. A. Osowole, "Synthesis, characterization, and magnetic and thermal studies on some metal(II) thiophenyl schiff base complexes," International Journal of Inorganic Chemistry, vol. 2011, Article ID 650186, 7 pages, 2011.

[53] L. Bellamy, The Infrared Spectra of Complex Molecules, Chapman and Hall, London, UK, 1975.
[54] J. R. Anacona and M. Lopez, "Mixed-ligand nickel(II) complexes containing sulfathiazole and cephalosporin antibiotics: synthesis, characterization, and antibacterial activity," International Journal of Inorganic Chemistry, vol. 2012, Article ID 106187, 8 pages, 2012.

[55] N. N. Greenwood and A. Earnshaw, "Coordination compounds," in Chemistry of the Elements, pp. 1290-1326, Butterworth-Heinemann, Oxford, UK, 2nd edition, 1997.

[56] A. B. P. Lever, Inorganic Electronic Spectroscopy, vol. 481, Elsevier, London, UK, 1986.

[57] N. S. Youssef and K. H. Hegab, "Synthesis and characterization of some transition metal complexes of thiosemicarbazones derived from 2-acetylpyrrole and 2-acetylfuran," Synthesis and Reactivity in Inorganic, Metal-Organic and Nano-Metal Chemistry, vol. 35, no. 5, pp. 391-399, 2005.

[58] N. Raman, K. Pothiraj, and T. Baskaran, "Synthesis, characterization, and DNA damaging of bivalent metal complexes incorporating tetradentate dinitrogen-dioxygen ligand as potential biocidal agents," Journal of Coordination Chemistry, vol. 64, no. 24, pp. 4286-4300, 2011.

[59] G. L. Miessler and D. A. Tarr, "Coordination compounds," in Inorganic Chemistry, vol. 642, pp. 315-316, Pearson Prentice Hall, New York, NY, USA, 1999.

[60] A. I. Mosa, M. M. Ibrahim, and S. A. Aldhlmani, "Spectroscopic and solution studies of some transition metal complexes of new 4-hydroxy coumarin semi- and thiosemicarbazone complexes," Journal of Solution Chemistry, vol. 42, no. 12, pp. 2364-2383, 2013.

[61] A. I. Mosa, A. A. A. Emara, J. M. Yousef, and A. A. Saddiq, "Novel transition metal complexes of 4-hydroxy-coumarin-3thiocarbohydrazone: pharmacodynamic of $\mathrm{Co}(\mathrm{III})$ on rats and antimicrobial activity," Spectrochimica Acta-Part A: Molecular and Biomolecular Spectroscopy, vol. 81, no. 1, pp. 35-43, 2011.

[62] K. Nakamoto, "Complexes of amino acids," in Spectroscopy and Structure of Metal Chelate Compounds, K. Nakamoto and S. McCarthy, Eds., pp. 194-197, Wiley Interscience, New York, NY, USA, 4th edition, 1986.

[63] D. Saïdana, M. A. Mahjoub, O. Boussaada et al., "Chemical composition and antimicrobial activity of volatile compounds of Tamarix boveana (Tamaricaceae)," Microbiological Research, vol. 163, no. 4, pp. 445-455, 2008.

[64] C. Walsh, Antibiotics: Action, Origin, Resistance, ASM Press, Washington, DC, USA, 2003.

[65] K. Drlica, M. Malik, R. J. Kerns, and X. Zhao, "Quinolonemediated bacterial death," Antimicrobial Agents and Chemother$a p y$, vol. 52, no. 2, pp. 385-392, 2008.

[66] H. G. Floss and T.-W. Yu, "Rifamycin-mode of action, resistance, and biosynthesis," Chemical Reviews, vol. 105, no. 2, pp. 621-632, 2005.

[67] A. R. M. Syahmi, S. Vijayarathna, S. Sasidharan et al., "Acute oral toxicity and brine shrimp lethality of elaeis guineensis jacq., (oil palm leaf) methanol extract," Molecules, vol. 15, no. 11, pp. 8111$8121,2010$.

[68] V. Elsyana, M. Bintang, and B. P. Priosoeryanto, "Cytotoxicity and antiproliferative activity assay of clove mistletoe (Dendrophthoe pentandra (L.) Miq.) leaves extracts," Advances in Pharmacological Sciences, vol. 2016, Article ID 3242698, 6 pages, 2016. 

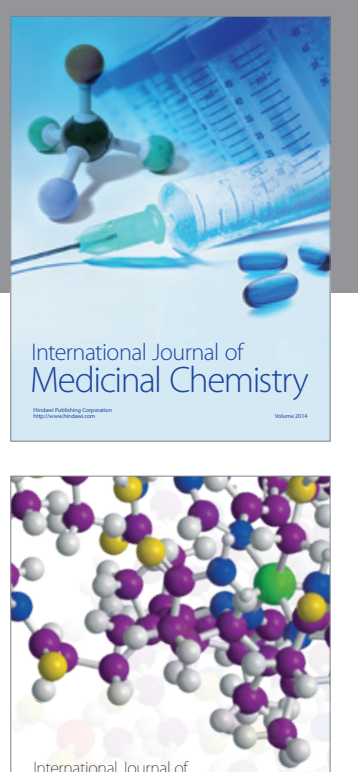

Carbohydrate Chemistry

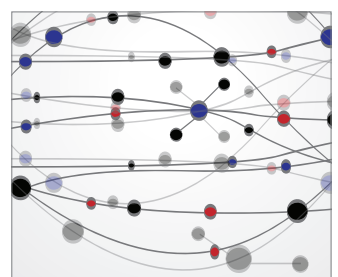

The Scientific World Journal
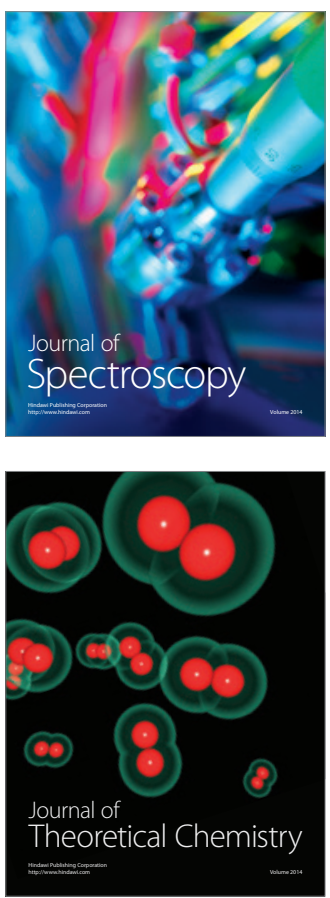
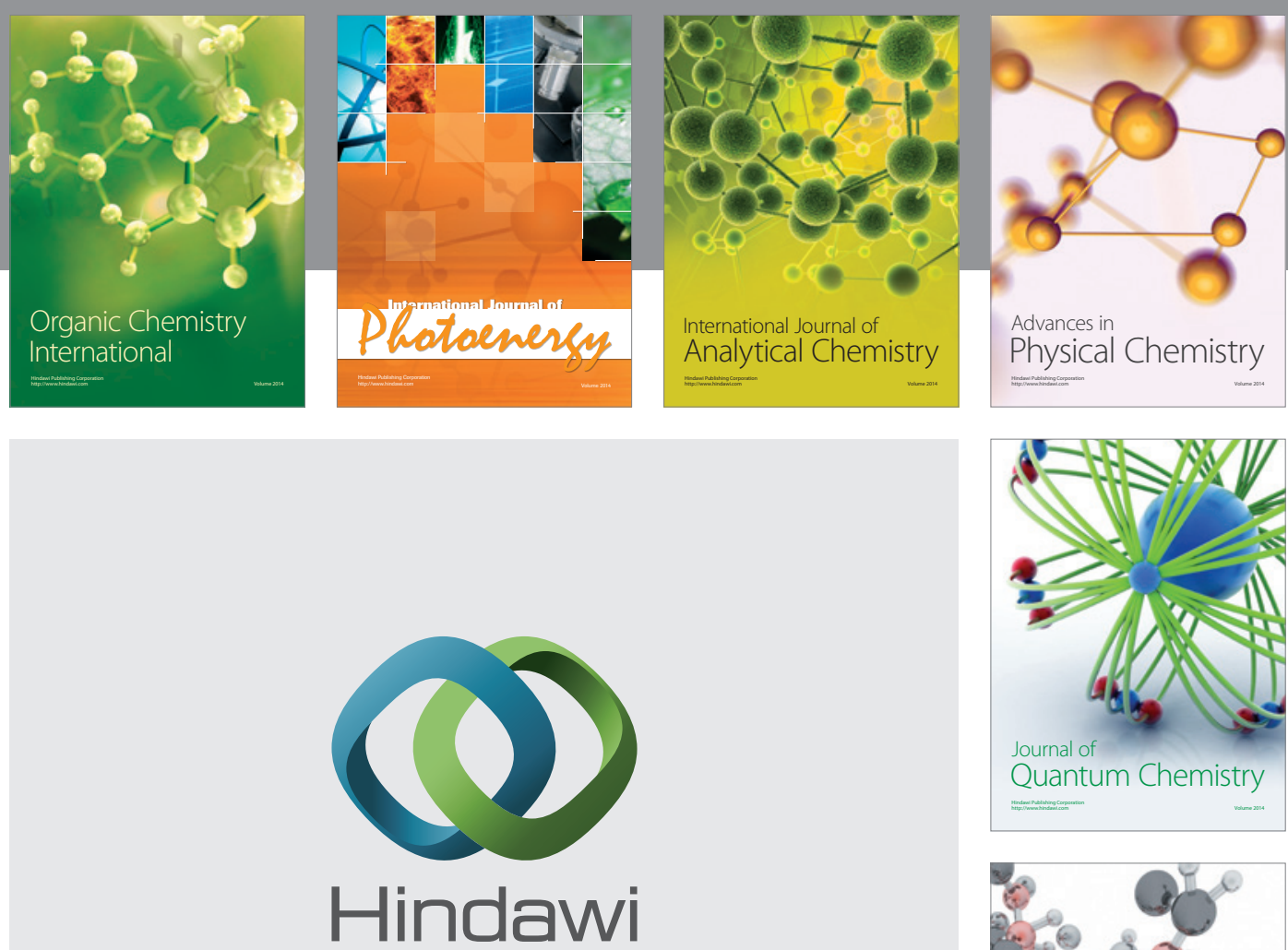

Submit your manuscripts at

https://www.hindawi.com

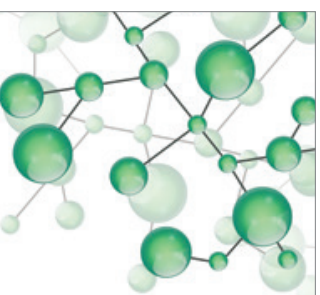

International Journal of

Inorganic Chemistry
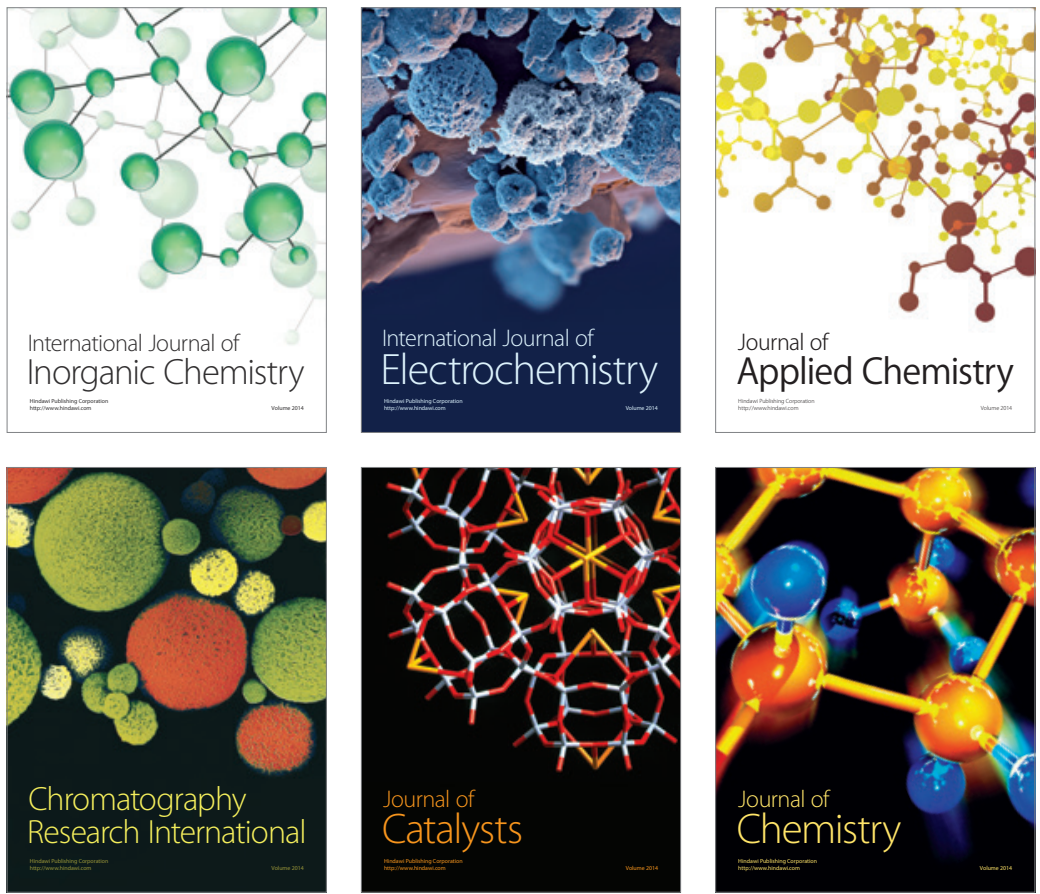

Journal of

Applied Chemistry
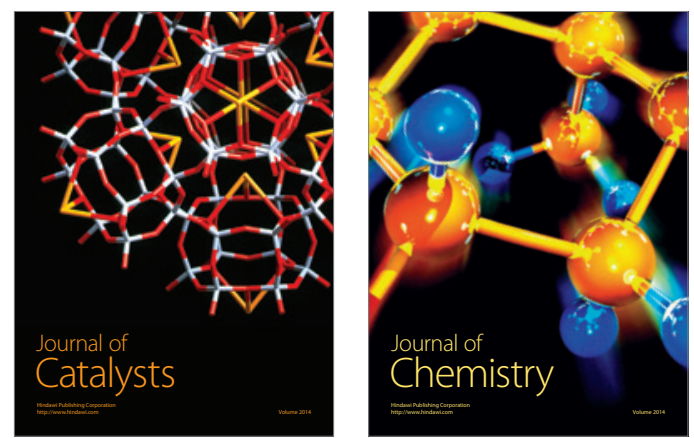
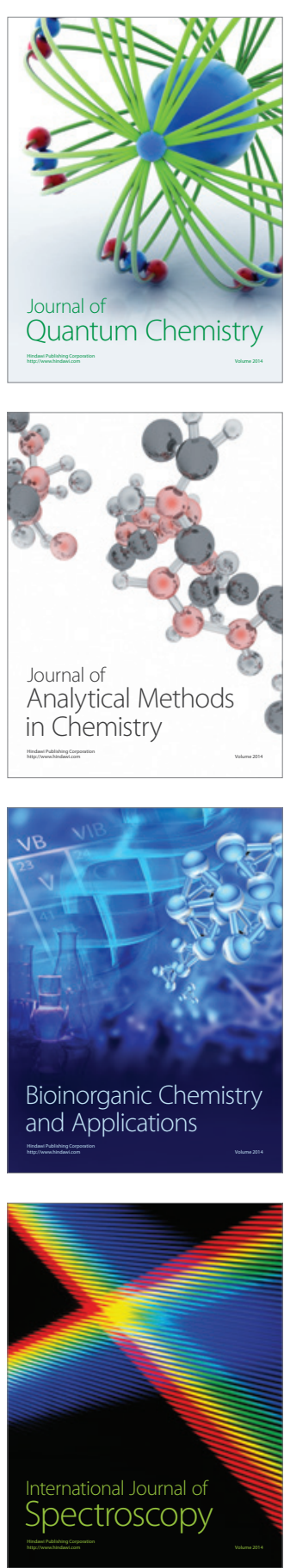